\title{
Exploring the link among food loss, waste and food security: what the research should focus on?
}

\author{
Fabio G. Santeramo ${ }^{*}$ (D)
}

\begin{abstract}
Food loss and food waste are highly debated topics and likely to stay in the research agendas for the next decades. Their relevance is not only important for developing economies, but also for developed economies, especially due to the impact that loss and waste have on the status of food security. In the present editorial, I comment on how research agendas should be shaped in order to focus on emerging issues, and put emphasis on the topics closely connected to the emerging literature on the circular economy.
\end{abstract}

Keywords: Agri-food system, Agri-food supply chain, Circular economy, Water-energy-food nexus

\section{Background}

During the last decades the growth of the agri-food sector has been parallel to several other dynamics, such as countries' specialization, trade openness, and socio-economic inequalities. These changes have not eliminated the threats for food insecurity, a complex and multi-faceted phenomenon [15]. Indeed, they have added further challenges on the global agenda: the share of food-insecure people is still high, with an estimate (before the pandemic) of 680 million people being food insecure [6] that are expected to increase after the pandemic.

Among the major threats that the global changes are imposing on food security, it is important to mention the increase in the amount of food lost and wasted. Wasting food is a relevant issue for (at least) two reasons: it emphasizes the need for economic efficiency, the necessity to produce foods for those who need it without losing (significant) shares of produced goods due to spoilage of inefficiencies in logistic; it calls for a reflection on the ethical concerns that the current production system imposes on our society.

*Correspondence: fabio.santeramo@unifg.it

University of Foggia, Via Napoli 25, 71122 Foggia, Italy
The terms "food loss" and "food waste" are frequently used as synonymous, while they refer to different aspects of the same problem as suggested in Schuster and Torero [23]. Food loss, both production and post-harvest losses, refers to the accidental reduction in the quantity and quality of food before consumption. Potential food losses are also associated with food lost, due to pests and diseases, limited harvesting techniques, price volatility, or food not produced, due to the lack of agricultural inputs [19-21]. Differently, food waste refers to the intentional discard of food suitable for the human consumption.

To put all these issues in one term, food waste and food loss are detrimental for the status of food security, and, by implying sustained prices [17], impact on the compositions of diets [3], that are sensitive to income and price changes [18, 24]. While the global demand for food grows, millions of people suffer from undernourishment worldwide [1]. About 1.3 billion tons of edible foodstuffs (one-third of the global food production) are lost or wasted along the food supply chain [9].

Food loss and waste may occur during production (e.g., pre-harvest, harvest, breeding), post-production procedures (e.g., handling, storage, transport), processing (e.g., canning, packaging, transformation), distribution 
(e.g., retail, transport), and consumption (e.g., preparation, table) [23]. The inefficient use of resources within the agri-food systems impacts on the three dimensions of sustainability: from the environmental perspective, food loss and waste contribute to natural resource depletion and environmental pollution; at the economic level, the impacts of food waste are substantial especially at the consumption and retail stages; from the social point of view, food loss and waste, by reducing food access and availability may undermine food security $[4,10]$.

The reduction of food loss and waste along the supply chain, from production to consumption, is essential to improve food security while reducing pressure on natural resources [9], as stated for the Sustainable Development Goals envisaged by the 2030 Agenda for Sustainable Development [25]. The global food losses and waste are constantly monitored ${ }^{1}$ on the basis of the Food Loss Index (FLI) and the Food Waste Index (FWI). While the FWI comprising the retail and consumption levels is still under development, the FLI considers food losses occurring from production up to the retail level.

\section{What the literature has already emphasized and what needs to be further investigated}

The first author that has investigated the connections between food loss and food security is likely to have been Nyambo [12], with the important claim farmers in Kenya, by reducing food losses (due to post-harvest grain handling technology) are capable of enhancing food security.

After this pioneering study, the linkages between food loss and waste and food security have remained underdebated for a couple of decades. At the beginning of the new millennium Marsh et al. [11] focused on the impact that food losses along the global food supply chains have on food security and concluded that food losses are consistent for the vast majority of traded agricultural commodities. These studies have legitimated the strand of literature devoted to exploring how food losses increase food insecurity in developing countries, the most dependent on trade and in need of innovations.

More recently, Eikenberry and Smith [5] pointed out that food recovery and donation programmes may help reducing the amount of wasted food, and thus contribute to improve the status of food insecurity in most developed countries.

Containing losses and waste would help cutting the use of resources (i.e. water, energy) used for food production,

\footnotetext{
${ }^{1}$ For instance, the FAO provides an in-depth look at what food is being lost and wasted, and where. The FAO's Food Loss and Waste database is a large collection of data on both food loss and food waste containing information and measures of food loss and waste across food products, stages of the value chain, and geographical areas.
}

with benefits for the environment and for the status of food security. In order to reduce food loss and food waste, governments are adopting legislative and non-legislative initiatives and consumer awareness campaigns [23] to favour the transition towards sustainable agri-food systems and supply chains that ensure food security in a green and circular economy perspective. For instance, countries in the European Union are committed to halve per capita food waste at the retail and consumer level and reduce food losses along the food production and supply chains by 2030, to meet the Sustainable Development Goals. To this end, since 2015, the European Commission took actions to prevent food losses and waste under the Circular Economy Action Plan, based on three major principles: reduce, reuse, and recycle (e.g., [14]).

Efficient containment policies along the entire agrifood supply chains may contribute to save water and energy and to implement an integrated resource use in a green economy [2]. Several topics are promising and should be explored more and more in order to follow new trends observed in the food industry $[19,20]$ : the development of improved food harvest, storage, processing, transport and retailing processes, the adoption of new technologies; the organization of farmers in cooperatives or professional associations; the promotion of awareness campaigns for retails and consumers; the development of communication strategies among all participants in food supply chains; the promotion of reuse and recycle strategies in a circular and green economy perspective. The recognition of sectoral interconnections may help to improve cross-sectoral collaborations to achieve longterm economic, environmental, and social goals [22].

Another issue that should be on the research agenda is the relationships linking water and energy use to the status of food security. The global agri-food systems consume large shares of water and energy for food production and supply chains. Agriculture accounts for $72 \%$ of all water withdrawals [26] and food production and supply chains are responsible of about $30 \%$ of total global energy consumption [6,7]. In addition, in the global energy mix, the fossil fuel production (highly waterintensive) is still dominant with respect to renewable energy sources (less water-intensive).

Understanding the water-energy-food security nexus is crucial to achieve the UN Sustainable Development Goals: the domains "water", "energy", "food" are strictly interrelated and the achievement of social, economic and environmental goals in a perspective of sustainable development depends on an efficient management of these resources [8]. Global projections indicate that-due to a growing population, a rapid economic development and the urbanization, the changes in diets and the climate change [8] - the demand for water is expected to increase 
by $55 \%$ by 2050 [13], the energy consumption is expected to grow by up to $50 \%$ by 2035 , and demand for food is expected to increase by $50 \%$ to feed the more than 9 billion people projected by 2050 [6]. Focusing on the nexus between water, energy, and food would help facing the global challenges that the globe.

To sum up, it is advisable to wisely orient the future research on understanding the interrelations between food loss and waste and food security. To this aim, scenario analyses would be useful to explore strategic decisions (e.g., policy, investment, technical intervention) planned or adopted to contain food loss and waste. In order to analyse the food loss/waste-food security nexus and assess the implications of containment policies, reliable, relevant and timely data is needed. Evidence-based analyses of the implications of food loss and waste on food security, supported by high-quality and available data, would provide key information to policymakers aimed at promoting environmentally, economically, and socially sustainable development.

\section{Acknowledgements}

Not applicable.

Authors' contributions

The author read and approved the final manuscript.

Funding

Not applicable.

Availability of data and materials

Not applicable.

\section{Declarations}

Ethics approval and consent to participate

Not applicable.

\section{Consent for publication}

Accept.

\section{Competing interests}

The author declares that there are no competing interests.

Received: 29 March 2021 Accepted: 13 April 2021

Published online: 22 April 2021

\section{References}

1. Abiad MG, Meho LI. Food loss and food waste research in the Arab world: a systematic review. Food Security. 2018;10(2):311-22.

2. Barbier EB. The green economy post Rio+ 20. Science. 2012;338(6109):887-8.

3. Caracciolo F, Santeramo FG. Price trends and income inequalities: will Sub-Saharan Africa reduce the gap? Afr Dev Rev. 2013;25(1):42-54.

4. Corrado S, Caldeira C, Eriksson M, Hanssen OJ, Hauser HE, van Holsteijn F, Liu G, Östergren K, Parry A, Secondi L, Stenmarck Å, Sala S. Food waste accounting methodologies: challenges, opportunities, and further advancements. Glob Food Sec. 2019;20:93-100.

5. Eikenberry N, Smith C. Attitudes, beliefs, and prevalence of dumpster diving as a means to obtain food by Midwestern, low-income, urban dwellers. Agric Hum Values. 2005;22(2):187-202.

6. FAO, IFAD, UNICEF, WFP, WHO. The State of Food Security and Nutrition in the World 2020. Transforming food systems for affordable healthy diets. Rome: FAO; 2020.

7. FAO. Global food losses and food waste. Rome: FAO; 2011.

8. FAO. The Water-Energy-Food Nexus. A new approach in support of food security and sustainable agriculture. Rome: FAO; 2014.

9. Gustavsson J, Cederberg C, Sonesson U, Van Otterdijk R, Meybeck A. Global food losses and food waste. Rome: FAO; 2011.

10. Kuiper M, Cui HD. Using food loss reduction to reach food security and environmental objectives - a search for promising leverage points. Food Policy. 2021;98:101915.

11. Marsh KS, Hammig MD, Singer NS. Estimates of international transport losses of world food supply. J Int Food Agribus Market. 2001;12(3):69-84.

12. Nyambo BT. Post-harvest maize and sorghum grain losses in traditional and improved stores in South Nyanza District, Kenya. Int J Pest Manag. 1993;39(2):181-7.

13. OECD. The Water Challenge: sharing a precious commodity. Paris: OECD; 2012.

14. Sakai S, Yoshida H, Hirai Y, Asari M, Takigami H, Takahashi S, Tomoda K, Peeler MV, Wejchert J, Schmidt-Unterseh T, Ravazzi Douvan A, Hathaway R, Hylander LD, Fischer C, Oh JG, Jinhui L, Chi NC. International comparative study of $3 R$ and waste management policy developments. J Mater Cycles Waste Manag. 2011;13:86-102.

15. Santeramo FG. On the composite indicators for food security: decisions matter! Food Rev Intl. 2015;31(1):63-73.

16. Santeramo FG. Food security composite indices: implications for policy and practice. Dev Pract. 2015;25(4):594-600.

17. Santeramo FG. Price transmission in the European tomatoes and cauliflowers sectors. Agribusiness. 2015;31(3):399-413.

18. Santeramo FG, Shabnam N. The income-elasticity of calories, macroand micro-nutrients: what is the literature telling us? Food Res Int. 2015;76:932-7.

19. Santeramo FG, Carlucci D, De Devitiis B, Seccia A, Stasi A, Viscecchia R, Nardone G. Emerging trends in European food, diets and food industry. Food Res Int. 2018;104:39-47.

20. Santeramo FG, Lamonaca E, Contò F, Stasi A, Nardone G. Drivers of grain price volatility: a cursory critical review. Agric Econ (AGRICECON). 2018;64(8):347-56.

21. Santeramo FG, Lamonaca E. On the drivers of global grain price volatility: an empirical investigation. Agric ECon (AGRICECON). 2019;65(1):31-42.

22. Santeramo FG, Searle S. Linking soy oil demand from the US Renewable Fuel Standard to palm oil expansion through an analysis on vegetable oil price elasticities. Energy Policy. 2019;127:19-23.

23. Schuster M, Torero M. Reducing food loss and waste. International Food Policy Research Institute (IFPRI), IFPRI book chapters 2016; 9780896295827-03

24. Shabnam N, Santeramo FG, Asghar Z, Seccia A. The impact of food price crises on the demand for nutrients in Pakistan. J South Asian Dev. 2016;11(3):305-27.

25. UNn. Sustainable development goals - 17 goals to transform our world. New York: United Nations; 2015.

26. UN-Water. Summary progress update 2021 -SDG 6 - water and sanitation for all. Geneva: UN-Water; 2021.

\section{Publisher's Note}

Springer Nature remains neutral with regard to jurisdictional claims in published maps and institutional affiliations. 